\title{
Towards a Unified Catalogue of Non-Technical Quality Attributes to Support COTS-Based Systems Lifecycle Activities
}

\author{
Juan Pablo Carvallo Vega \\ ETAPATELECOM \\ Calle Larga y Ave. Huayna Capac, edif. Banco Central del Ecuador, 1ra. Planta alta \\ Cuenca, Ecuador \\ jpcarvallo@etapatelecom.net \\ Xavier Franch, Carme Quer \\ Universitat Politècnica de Catalunya (UPC) \\ c/ Jordi Girona 1-3 (Campus Nord, C6) E-08034 Barcelona (Catalunya, Spain) \\ \{franch, cquer\}@lsi.upc.edu
}

\begin{abstract}
Several activities of the COTS-based systems lifecycle are supported not only by the analysis of their technical quality but also (and sometimes mostly) by considering how they fulfill some non-technical quality features considered relevant (licensing, reputation, costs and similar issues). Whilst many catalogues of technical quality features exist, it is not the case for non-technical ones, which are often managed in an ad-hoc form. In a recent work, we proposed a catalogue of non-technical quality features, designed to integrate smoothly into the ISO/IEC 9126-1 standard. In this paper, we detail the process used for the composition of the catalogue, which embraces the inclusion of several non-technical quality features already identified in the literature as well as others which have emerged form our own experience in industrial COTS components selection processes. We also outline some potential applications of the resulting catalogue, intended to support several activities of the COTS-based systems lifecycle. Finally, we describe a COTS selection process carried out in a
\end{abstract} telecommunications company.

\section{Introduction}

Although non-technical requirements have been considered relevant in the establishment of the basic criteria to support some COTS-based systems activities [13][19], most of the work in the field has focused in the technical aspects of quality, paying little attention to the analysis and categorization of non-technical issues [14].

Non-technical quality features are relevant for several activities that take place during COTS-based systems development, to name a few: in an early stage, they can be used during the estimation of the project budget and the overall architecture of the system; during negotiation, they may provide the basis to set the project scope and to establish the responsibility of the parties involved; during project development, they may support the clarification of disagreements on the contract; finally, at project wrap-up, they can be useful not only to assess the accomplishment of the initial stated objectives, but also as the basis to negotiate the future relationships with suppliers.

Because of this, the analysis of non-technical aspects of COTS components, their categorization and their representation is more than well-justified. In this paper we claim that technical and non-technical aspects should be dealt similarly using a common framework instead of different assets. To achieve this goal, we propose to extend the ISO/IEC 9126-1 catalogue of technical quality features [9] with non-technical features following the same layout than in this standard. We follow the process shown in fig. 1 and described in more detail in [6]:

1) We fix first just the higher-level features (called characteristics and subcharacteristics in the standard). We call this catalogue the non-technical extension of the ISO/IEC catalogue (NT-ISO/IEC catalogue for short).

2) Then, we enrich the NT-ISO/IEC catalogue with some more subcharacteristics and attributes that appear frequently in COTS selection processes obtaining thus an intermediate, highly reusable catalogue. We call it the extended NT-ISO/IEC catalogue and it is the counterpart of the extended ISO/IEC catalogue that we proposed for technical features in [4].

3) Last, each particular selection process extends these catalogues by decomposing their features into others, adding new ones, hiding others that are not relevant for the problem at hand, etc. The result is called customized catalogues, both ISO/IEC and NT-ISO/IEC.

We remark the homogeneous treatment of technical and non-technical aspects which is one of the key points of our approach. The complete version of this catalogue can be found at [5]. 


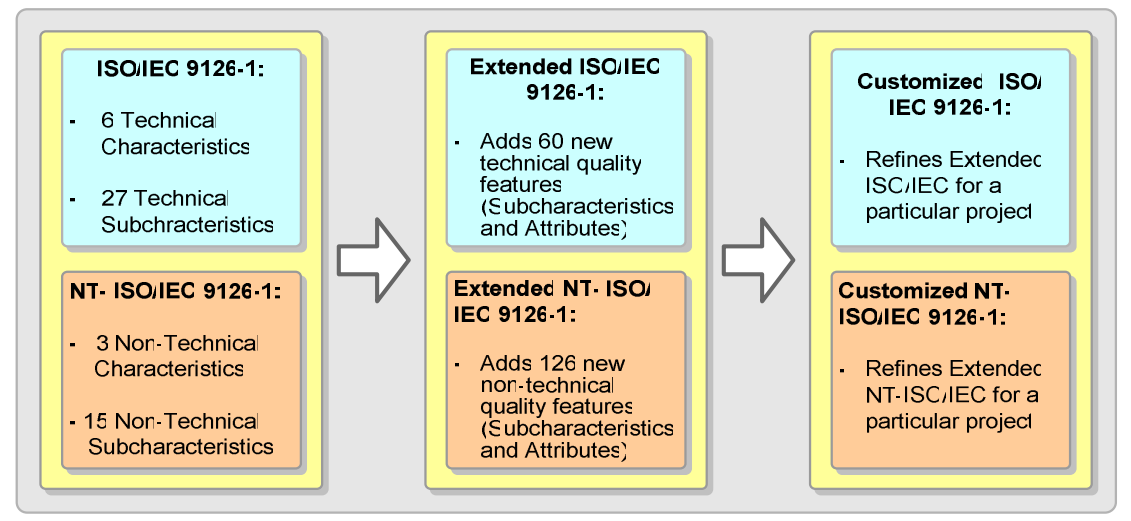

Figure 1: The different catalogues found [6].

The rest of the paper is structured as follows. Sections 2 and 3 present the research method and the related work; section 4 introduces the ISO/IEC 9126-1 quality framework; section 5 addresses the construction process and outlines the contents of the catalogue; section 6 presents a case study; and finally section 7 gives some conclusions and future lines of work.

\section{Research Method}

The research carried out to formulate the proposal has combined literature survey with action-research through different industrial experiences. We may divide the research performed into three phases:

Phase I. Detection of the problem. In the period from 2002 to 2005, we participated in 7 projects [6], in which we applied the ISO/IEC-9126-1-based IQMC method [8] to construct quality models (QM) to support different activities of the development of COTS-based systems (evaluation of COTS components, requirements elicitation, ...). As a result we built the extended ISO/IEC catalogue (see fig. 1) adding 60 subcharacteristics and attributes to the standard. But at the same time, we discovered that non-technical requirements were playing a crucial role in the selection of coarse-grained COTS components and especially in Enterprise Applications such as ERP systems, CRM tools, etc. Two short examples that illustrate this situation are: in a project to select a Document Management Tool, the only two candidates to be selected were chosen because they had a special license agreement with the University where they were to operate; in a project to select a Requirements Management Tool, there was a non-negotiable requirement for the suppliers to have a site in Spain. Since the ISO/IEC 9126-1 standard does not address these nontechnical issues, we were forced to use different artifacts yielding to some management problem which we thought were avoidable.

Phase II. Formulation of a solution. We decided to tackle the problem as mentioned in the introduction, adopting the hierarchical structure of characteristics, subcharacteristics and attributes of the ISO/IEC 9126-1 standard. Whilst we conducted some of our projects, we built a catalogue of non-technical quality features and refined its procedure of use. Thus, we arrived to the extended NT-ISO/IEC catalogue.

Phase III. Validation of the solution. The catalogue and the procedure were validated during our last industrial experience, the very large-scale one done in the mark of the telecommunications company, which we present in section 6. The project is still under development but the selection phase of some of the COTS components has successfully finished. We remark as especially challenging the size of the project (10'000.000 dollars for an expected number of 100.000 users) and the size of the corresponding artifacts (5 different QMs for different COTS components domains, encompassing over 1832 quality features), as well as the fact that it was an on-line participation: the proposal presented in this paper has been really used throughout the project and decisionmaking was done in the basis of its outcome.

\section{Related Work}

There are other works that also address non-technical quality features, see table 1 for a comparison of the some of the proposals reviewed in our research. Most of these approaches pursue very dissimilar objectives and tackle different problems. In [2] authors explore some commercial COTS vendors web pages and identify some non-technical features with the aim of evaluating the quality of the information provided by COTS suppliers in relation to technical ones. Also in [17] authors identify and categorize a set of non-technical features, to provide a framework for the classification of COTS components. The ISO/IEC 12119 [10] standard, establishes a set of quality requirements for software packages and instructions to test them based on the proposed requirements. 
Other works propose lists of non-technical features for the evaluation of COTS components. In [11] a list of 12 attributes classified in 3 categories (Business issues, Marketplace variables, and Vendor issues) is deduced and classified from interviews with 7 organizations. In this work the idea behind the study was to identify the features that are relevant in the selection of software products, in order to reuse the list of attributes in selection processes. In [15] a framework for the evaluation of software tools is presented, and it is applied to the domain of the tools that give support to component based software development. In one of the activities of the approach, they use a checklist of evaluation criteria, independent of the domain, including 32 non-technical attributes classified into 6 categories (business, external reference, vendor support, financial, emplacement and tool lifespan issues).

Also in [16] the aim is to provide criteria for the selection of COTS components in the supply chain management domain. Criteria are divided in primary and secondary drivers according to its importance for the selection process. Primary drivers include 24 attributes classified in 5 categories: technology, costs, features, customization and, support and services. Secondary drivers include 17 attributes classified in 4 categories: vendor vision, industry covered, vendor strength and others. This proposal also includes definitions for all the drivers in order to clarify their semantics and also metrics and weights to be used on their assessment. This important aspect is missing in the other approaches except for the case of [14] that also includes a weighting model to support quality features evaluation. To complete the approach, [16] provides a decision model designed to support the selection of components based on the metrics and weights assigned to quality features.

We remark several facts concerning table 1:

- All of the proposals (except for [17]) include a mixture of technical as well as non-technical quality features, without a clear separation among them. This fact endorses our believe that the provision of a common framework for the management of both types of quality features is reasonable. However the lack of a separation of concerns makes the final catalogue less structured and confusing for the final user. The only approach that draws a clear line between technical a non-technical quality features is [11].

- Some of the models (e.g. [11, 15] ) include some quality features which, because of their nature, cannot be categorized as technical or non-technical ones, at least not for the evaluation of components or their suppliers (e.g. customer expectations, customer experience, organizational culture, people attitude, project specific and independent features, etc.). However some of these quality features can be good to support other activities such as risk and cultural change management.
- Most of the approaches are not well leveled, they mix top level quality features with lower level ones, or even with examples of the values that some of the metrics of quality features can adopt (e.g. the "FMCG, Auto., Elec., Chem., High-tech, Service, etc." attribute categorized under the "Industry Covered" secondary driver in [16] ).

- Overlapping of quality features, defined as the condition in which a given quality feature influences on the evaluation of more than other higher-level ones, is an important characteristic when building QMs. Several approaches (e.g., [18], [10]) consider overlapping a property both natural and necessary. However, it is important to remark that in most of these approaches overlapping occurs also among technical and non-technical quality features.

\section{The ISO/IEC 9126-1 Quality Standard}

The main idea behind the ISO/IEC 9126-standard is to use quality models, composed of three types of quality features (characteristics, subcharacteristics and attributes), as a framework for software evaluation. The standard fixes a set of six characteristics (functionality, reliability, usability, efficiency, maintainability and portability) decomposed into a first level of sucharacteristics (such as security, portability, etc). All quality features are intended for the evaluation of the technical quality of software, without mention or support for the evaluation of nontechnical quality aspects.

The standard is not precise at some points, as for example if multilevel hierarchies of subcharacteristics or attributes are allowed. For this reason we have felt compelled to take some decisions about which should be the organization of an ISO/IEC-based quality model [1]. We remark:

- Characteristics are non-measurable quality features used to classify the rest of entities of the model.

- Subcharacteristics are quality features that may be decomposed into other subcharacteristics or alternatively into attributes. Subcharacteristics are also used for classification purposes.

- Hierarchies of subcharacteristics and attributes are allowed with no restrictions about number of levels.

- Attributes can be derived or basic. Basic attributes are directly measurable quality features which can be objectively measured.

- Derived attributes are non-directly measurable quality features. Metrics can be objective or subjective.

- Overlapping of quality features is allowed for quality attributes.

- Quality attributes belonging to more than one subcharacteristic can be measured with different metrics for each case. 


\begin{tabular}{|c|c|c|c|c|c|c|c|c|c|c|c|}
\hline Criteria & [18] & [10] & [13] & [11] & [14] & [15] & [20] & [17] & [18] & [16] & [12] \\
\hline Levels & 2 & 4 & 2 & 3 & 2 & 2 & 2 & 1 & 3 & 3 & 4 \\
\hline \multicolumn{12}{|l|}{ Levels Names } \\
\hline Level 1 & $\begin{array}{l}\text { Perspectives } \\
\text { / Grouping } \\
\text { characteris- } \\
\text { tics }\end{array}$ & Subclauses & $\begin{array}{l}\text { Evaluation } \\
\text { Criteria } \\
\text { Groups }\end{array}$ & $\begin{array}{l}\text { Characteris- } \\
\text { tics/Factors }\end{array}$ & $\begin{array}{l}\text { Socio- } \\
\text { technical } \\
\text { Criteria }\end{array}$ & \begin{tabular}{|l} 
Tool \\
evaluation \\
issues
\end{tabular} & $\begin{array}{l}\text { Things to } \\
\text { Measure }\end{array}$ & $\begin{array}{l}\text { No ISO/IEC } \\
9126 \\
\text { attributes }\end{array}$ & Category & Divers & N/A \\
\hline Level 2 & $\begin{array}{l}\text { Characteris- } \\
\text { tics }\end{array}$ & N/A & $\begin{array}{l}\text { Evaluation } \\
\text { Criteria }\end{array}$ & N/A & $\mathrm{N} / \mathrm{A}$ & $\begin{array}{l}\text { Evaluation } \\
\text { criteria }\end{array}$ & & $\mathrm{N} / \mathrm{A}$ & Attribute & Drivers & $\mathrm{N} / \mathrm{A}$ \\
\hline Level 3 & N/A & $N / A$ & $N / A$ & N/A & $\mathrm{N} / \mathrm{A}$ & $\mathrm{N} / \mathrm{A}$ & & $\mathrm{N} / \mathrm{A}$ & $\mid \begin{array}{l}\text { Possible } \\
\text { Values }\end{array}$ & Drivers & N/A \\
\hline Level 4 & $\mathrm{~N} / \mathrm{A}$ & N/A & $\mathrm{N} / \mathrm{A}$ & $\mathrm{N} / \mathrm{A}$ & $\mathrm{N} / \mathrm{A}$ & $\mathrm{N} / \mathrm{A}$ & & $\mathrm{N} / \mathrm{A}$ & $\mathrm{N} / \mathrm{A}$ & N/A & N/A \\
\hline Total Quality Features (QF) & 27 & 78 & 12 & 45 & 21 & 65 & 30 & 9 & 56 & & 122 \\
\hline \multicolumn{12}{|l|}{ Number of QF per level } \\
\hline Level 1 & 5 & 7 & 4 & 3 & 4 & 8 & 4 & 9 & 4 & 2 & 3 \\
\hline Level 2 & 22 & 22 & 8 & 30 & 17 & 57 & 26 & & 10 & 9 & 17 \\
\hline Level 3 & & 29 & & 12 & & & & & 42 & 41 & 73 \\
\hline Level 4 & & 20 & & & & & & & & & 29 \\
\hline \multicolumn{12}{|l|}{ QFs coverage } \\
\hline $\begin{array}{l}\text { Technical Functional } \\
\text { (TF) }\end{array}$ & 2 & 8 & 1 & 1 & 11 & 6 & 3 & 2 & & & 0 \\
\hline \begin{tabular}{|l|} 
Technical No \\
Definable \\
\end{tabular} & & & & & & 1 & 1 & & & & \\
\hline Non-Technical & 4 & 26 & 2 & 16 & 6 & 33 & 21 & 9 & 56 & & 34 \\
\hline Other & & & & 17 & & 12 & 4 & & & & 21 \\
\hline \multicolumn{12}{|l|}{ Overlapping of QF } \\
\hline Non-Technical \& TNF & 4 & 15 & & & & 2 & & 2 & & & 3 \\
\hline Non-Technical \& TF & 0 & 0 & & & & & 2 & & & & \\
\hline TF\&TNF & & & & & & \begin{tabular}{|l}
1 \\
\end{tabular} & 3 & & & & \\
\hline Level of detail & Basic & Medium & Informative & Medium & Basic & Medium & Basic & Basic & Detailed & Detailed & Detailed \\
\hline Leverage of the model & Leveled & $\begin{array}{l}\text { Not leveled, } \\
\text { Missing QF } \\
\text { in some } \\
\text { higher levels }\end{array}$ & $\begin{array}{l}\text { Not leveled, } \\
\text { not intended }\end{array}$ & Leveled & Leveled & Not leveled & $\begin{array}{l}\text { Not leveled, } \\
\text { not intended }\end{array}$ & One level & $\begin{array}{l}\text { Highly- } \\
\text { leveled }\end{array}$ & $\begin{array}{l}\text { Highly- } \\
\text { leveled }\end{array}$ & $\begin{array}{l}\text { Highly- } \\
\text { leveled }\end{array}$ \\
\hline Are metrics provided & Not & Not & Not & Not & Not & Not & Not & Not & Not & Yes & Not \\
\hline Objective of the proposal & $\begin{array}{l}\text { Identification } \\
\text { of evaluation } \\
\text { attributes } \\
\text { which are } \\
\text { influenced by } \\
\text { stakeholders } \\
\text { personal } \\
\text { values }\end{array}$ & $\begin{array}{l}\text { Definition of } \\
\text { a set of } \\
\text { requirements } \\
\text { to be used in } \\
\text { the } \\
\text { evaluation of } \\
\text { software } \\
\text { packages }\end{array}$ & $\begin{array}{l}\text { Propose a } \\
\text { method for } \\
\text { cOTS } \\
\text { selection } \\
\text { (includes } \\
\text { examples of } \\
\text { evaluation } \\
\text { criteria) }\end{array}$ & $\begin{array}{l}\text { Identification } \\
\text { of COTS } \\
\text { evaluation } \\
\text { criteria. } \\
\text { Statistic } \\
\text { analysis to } \\
\text { select COTS } \\
\text { criteria }\end{array}$ & $\begin{array}{l}\text { Propose a } \\
\text { method for } \\
\text { cOTS } \\
\text { selection, } \\
\text { provide } \\
\text { evaluation } \\
\text { criteria to } \\
\text { support the } \\
\text { process } \\
\end{array}$ & $\begin{array}{l}\text { Identification } \\
\text { of COTS } \\
\text { evaluation } \\
\text { criteria }\end{array}$ & $\begin{array}{l}\text { Identification } \\
\text { of aspects to } \\
\text { be measured } \\
\text { in COTS- } \\
\text { based } \\
\text { systems } \\
\text { development }\end{array}$ & $\begin{array}{l}\text { Identification } \\
\text { of COTS } \\
\text { classification } \\
\text { criteria }\end{array}$ & $\begin{array}{l}\text { Identification } \\
\text { of COTS } \\
\text { classification } \\
\text { criteria }\end{array}$ & \begin{tabular}{|l|} 
Identify \\
COTS \\
evaluation \\
criteria. \\
Application in \\
the domain \\
of supply \\
chain \\
solutions \\
\end{tabular} & $\begin{array}{l}\text { Identification } \\
\text { of COTS } \\
\text { selection } \\
\text { criteria }\end{array}$ \\
\hline Context of the proposal & $\begin{array}{l}\text { Australian } \\
\text { ISP } \\
\text { Telecommu- } \\
\text { nications } \\
\text { company } \\
\end{array}$ & $\begin{array}{l}\text { International } \\
\text { standard } \\
\text { committee }\end{array}$ & $\begin{array}{l}\text { Research } \\
\text { group }\end{array}$ & $\begin{array}{l}\text { Research } \\
\text { group }\end{array}$ & $\begin{array}{l}\text { Zambian } \\
\text { Ministry of } \\
\text { Finance and } \\
\text { National } \\
\text { Planning } \\
\end{array}$ & $\begin{array}{l}\text { Research } \\
\text { group (with } \\
\text { paricipation } \\
\text { of industrials) }\end{array}$ & $\begin{array}{l}\text { Workshop on } \\
\text { COTS-Based } \\
\text { Systems }\end{array}$ & $\begin{array}{l}\text { Research } \\
\text { group }\end{array}$ & $\begin{array}{l}\text { Research } \\
\text { group }\end{array}$ & $\begin{array}{l}\text { Technology } \\
\text { transfer and } \\
\text { research } \\
\text { organization }\end{array}$ & $\begin{array}{l}\text { Technology } \\
\text { transfer and } \\
\text { research } \\
\text { organization }\end{array}$ \\
\hline
\end{tabular}

Table 1: Comparison of different proposals.

\section{Composing a Catalogue of Non-Technical Quality Features}

We have developed our proposal departing from the catalogues of non-technical quality features reviewed in section 3. In order to build the final catalogue, we have used some of the QM composition rules proposed in [4]. More concretely, we have performed two main activities:

- Activity 1: Comparison, consolidation and composition of existing catalogues. Resulting from this activity a catalogue of 169 non-technical quality features, structured in 5 levels, was obtained. The departing catalogue includes 3 quality features in the first level and 19 in the second one.

- Activity 2: Extension of the catalogue considering aspects not covered in other proposals. In this activity we have considered our industrial experiences. As a result we obtained an enriched catalogue with over 180 quality features structured in 6 levels, respecting the 3 quality features included in the first level of the previous catalogue, but only with 15 quality features in the second level. This enriched catalogue was later compressed to a catalogue of 144 quality features structured in 5 levels (the number of features in the two higher levels did not change), after the analysis of the evaluation metrics required for its quality features.

The next sections further detail these activities.

\subsection{Comparison, Consolidation and Compo- sition}

This first activity was especially hard due to several problems that emerged, which can be seen as drawbacks of the previous catalogues:

- The semantic ambiguity of the quality features included. The vast majority of the features included in the mentioned proposals were not defined as required 
to clarify their precise meaning. This makes difficult the comparison of some attributes included in the catalogues, and thus, the identification of similar ones.

- The absence of a clear separation among technical and non-technical quality features. It was mentioned in section 3 that most of the existing proposals group quality features of different kinds into a single hierarchy (e.g. technical functional, technical nonfunctional and non-technical), making it difficult in some cases to identify their real nature.

- The lack of a well-structured hierarchy: This is a common flaw of most of the proposals. In concrete we have found the need to convert siblings into parents and children in several occasions, to introduce some features to leverage the models and to remove some features since they were examples of possible values that the metrics of their parents may adopt, instead of lower-level attributes.

- The presence of very abstract quality features. Many of these proposals include quality features which due to their level of abstraction are not easy to measure, at least not in an objective way. In other to do so, they require to be decomposed into more basic attributes.

- Some of the quality features reference more than one quality concept at the time. It became clear after a short review that some of the quality features included in the proposals have to be split into several ones because they represent more than one quality concept at the same time.

To tackle these problems we followed an iterative process composed of five steps:

- Step 1: Convert each of the proposals to a common format and schema. Each of the proposals was exported to an Excel sheet, and their hierarchies aligned into columns. Quality features were sequentially numbered and also assigned a unique identifier, following a numbering schema of levels and sublevels (see table 2, three leftmost columns). Finally, some additional columns were added to the schema (see table 2, two rightmost columns), to make room for the inclusion of supplementary information to be gathered in the next steps.

- Step 2: Leverage of the proposals. Since the hierarchies in most of the case were not well structured, we had to take some actions to leverage the models and make them more understandable. Some examples in relation to the [10] approach are:

- The division of the System software and other software attribute categorized under the Required System subcharacteristic, into two separated attributes, one for each type of software.

- The addition of the leveraging Hardware and Software subcharacteristics, under the Required System subcharacteristic, to clearly split these two different platform-related quality concepts.

- The categorization of the System Software and Other Software attributes under the leveraging subcharacteristic Software.

- The adoption of the example attribute User Interface, as a lower-level attribute of the Statements on Usability subcharacteristic in the same standard.

\begin{tabular}{|c|c|c|c|c|c|c|c|}
\hline Id & Lev & el N & lumb & & Quality Features [10] (excerpt) & Type & $\begin{array}{c}\text { If } \\
\text { Technical, } \\
\text { which type }\end{array}$ \\
\hline 1 & 1 & & & & Identifications and Indications & NT & \\
\hline 2 & 1 & 1 & & & Identification of the product description & NT & \\
\hline 3 & 1 & 2 & & & Product identification & NT & \\
\hline 4 & 1 & 2 & 1 & & Name & NT & \\
\hline 5 & 1 & 2 & 2 & & Version & T-NT & NF \\
\hline 6 & 1 & 2 & 3 & & Variant & T-NT & NF \\
\hline 7 & 1 & 3 & & & Supplier & NT & \\
\hline 8 & 1 & 3 & 1 & & Name & NT & \\
\hline 9 & 1 & 3 & 2 & & Address & NT & \\
\hline 10 & 1 & 4 & & & Work Task & NT & \\
\hline 11 & 1 & 5 & & & Conformity to requirements documents & NT & \\
\hline 12 & 1 & 6 & & & Required System & NT & \\
\hline 13 & 1 & 6 & 1 & & $\begin{array}{l}\text { Hardware } \\
\quad \text { Processing Unit including co- }\end{array}$ & T-NT & NF \\
\hline 14 & 1 & 6 & 1 & 1 & processors & T-NT & NF \\
\hline 15 & 1 & 6 & 1 & 2 & $\begin{array}{l}\text { Main memory size } \\
\text { Types and sizes of peripheral }\end{array}$ & T-NT & NF \\
\hline 16 & 1 & 6 & 1 & 3 & storage & T-NT & NF \\
\hline 17 & 1 & 6 & 1 & 4 & Extension cards & T-NT & NF \\
\hline 18 & 1 & 6 & 1 & 5 & Input and output equipment & T-NT & NF \\
\hline 19 & 1 & 6 & 1 & 6 & Network environment & T-NT & NF \\
\hline 20 & 1 & 6 & 2 & & Software & T-NT & NF \\
\hline 21 & 1 & 6 & 2 & 1 & System software & T-NT & NF \\
\hline 22 & 1 & 6 & 2 & 2 & Other software & T-NT & NF \\
\hline 23 & 1 & 7 & & & Interfaces to other products & $\mathrm{T}$ & $\mathrm{F}$ \\
\hline 24 & 1 & 8 & & & Items to be delivered & NT & \\
\hline 25 & 1 & 9 & & & Installation & T-NT & NF \\
\hline 26 & 1 & 10 & & & Support & T-NT & NF \\
\hline 27 & 1 & 11 & & & Maintenance & T-NT & NF \\
\hline 45 & 4 & & & & Statements on usability & $\mathrm{T}$ & NF \\
\hline 46 & 4 & 1 & & & User interface & $\mathrm{T}$ & NF \\
\hline 47 & 4 & 1 & 1 & & Interface name & $\mathrm{T}$ & NF \\
\hline 48 & 4 & 1 & 1 & 1 & Command line & $\mathrm{T}$ & NF \\
\hline 49 & 4 & 1 & 1 & 2 & Menu & $\mathrm{T}$ & NF \\
\hline 50 & 4 & 1 & 1 & 3 & Windows & $\mathrm{T}$ & NF \\
\hline 51 & 4 & 1 & 1 & 4 & Function Key & $\mathrm{T}$ & NF \\
\hline 52 & 4 & 1 & 1 & 5 & Help Function & $\mathrm{T}$ & NF \\
\hline
\end{tabular}

Table 2: Common schema used to format the approaches.

- Step 3: Identification of the types of quality features. Given that most of the approaches group together different types of quality features, the next step was to recognize non-technical ones. The mnemonics NT (for non-technical), T (for technical), NT-T (for features which include a technical and a non-technical component) and $\mathrm{O}$ (for other) were used to mark the different types of quality features (see table 2). The NT-T notation was mainly used in the cases of subcharacteristics grouping both technical and nontechnical quality features at the same time (e.g. the Quality subcharacteristic of [20] which included both the technical Product Quality and the non-technical Service Quality attributes). 
- Step 4: Classification of technical quality features as functional and non-functional. Technical quality features were further categorized as functional and non-functional, in relation to the characteristics and subcharacteristics of the ISO/IEC 9126-1 quality standard. In this case the mnemonics $\mathrm{F}$ and NF were use to mark the attributes (table 2, rightmost column).

- Step 5: Composition into a final catalogue. The QM composition rules presented in [4] have been used for this purpose, although three basic situations are worth to be mentioned:

- Quality features representing the same quality concept were placed together in the same row.

- Quality features representing similar concepts were nested under a common parent.

- Quality features representing different quality concepts were placed into separated rows.

In all of these cases, references to the original models were added for keeping traceability to their sources (see table 3 for an excerpt of the resulting model). It is worth to remark that some of the quality features included in the proposals where not included in the process. This occurred whenever they were considered to ambiguous or in relation to aspects outside the scope of this catalogue, e.g. the Comparison with Other Tools or the Gaining Experience attributes included in [15].

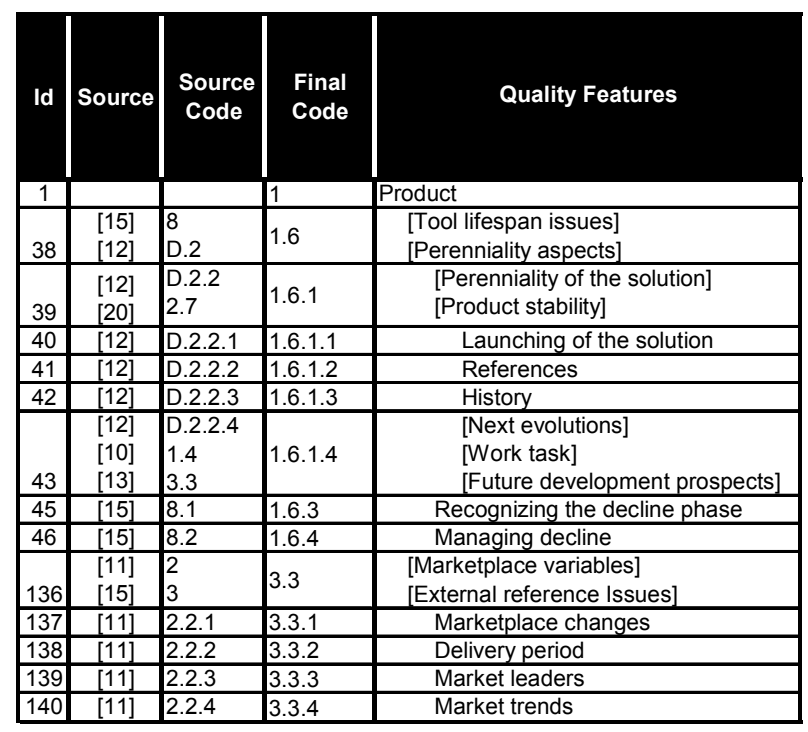

Table 3: An excerpt of the compound catalogue.

It is important to remark that after the process was concluded it became evident the small number of coincidences among quality features in the proposals, only 19 out of the 169 non-technical quality features included in the final catalogue were present in more than one of the proposals. Only 4 of these quality features were identified in 3 catalogues, and only 3 in 4 of them. This can be interpreted as a consequence of the fact that they were proposed to address different problems, but even in the proposals addressing the same problem (e.g., [11] and [13]) the large dispersion of quality features was evident.

\subsection{Extension}

In this second activity we have arranged non-technical attributes in an ISO/IEC 9126-1 tree-like structure, thus the catalogue includes high-level characteristics and subcharacteristics, and also lower-level attributes. The principles and guidelines used to build and refine the resulting NT-ISO/IEC catalogue are detailed in [21]. Next we summarize the most important ones:

- A quality feature represents a single concept, about which enterprises want to have information.

- A quality feature must be labelled with a unique, descriptive name.

- Each quality feature must be described with a definition, description or statement of purpose.

- Quality features corresponding to a same level that have simpler metrics, may be compressed into quality features with more complex metrics.

In addition, we considered as overall design principles:

- Uniformity. Easy integration of our catalogue of nontechnical features with the ISO/IEC 9216 hierarchy.

- Leverage. The model should maintain a balanced degree of abstraction at each level of the hierarchy.

The top-level hierarchy of the NT-ISO/IEC catalogue is presented in table 4 . It has been structured into 3 characteristics: Supplier, Costs, and Product which group non-technical quality features required to measure the supplier capacity to address and support the project, the implementation costs and the out-of-the-box quality and effort required to get the component running. These three top-level characteristics have been further decomposed into 15 subcharacteristics (see table 4). Similarly to nontechnical characteristics, some of the subcharacteristics have been identified in the reviewed approaches, whiles other where included in our approach to leverage the hierarchy required to embrace some of the acknowledged lower-level attributes.

In [1] we have shown the possibility of extending the ISO/IEC catalogue with up to 60 new subcharacteristics and attributes that arise virtually always in COTS selection. This extended ISO/IEC catalogue makes the selection process more efficient since more quality features are available from the very beginning. We have used the same idea for the NT-ISO/IEC catalogue obtaining thus the extended NT-ISO/IEC catalogue which adds 126 non-technical quality features to the 18 starting ones. As in the technical catalogue case, we have checked that these quality features are applicable to most selection processes. The process used extends the NT-ISO/IEC with 
additional lower-level subcharacteristics, basic and derived attributes, metrics and relationships among quality features is detailed in [3] [6], the complete version of the resulting catalogue can be found at [5]. Figure 2 depicts the intersection of the different catalogues explored, in relation with our proposal. Finally, it is important to remark that some of the existing quality features, the ones with simpler metrics (usually Boolean metrics) were collapsed in quality features with more complex metrics (e.g. enumerate metrics, function metrics, ...).

\begin{tabular}{|l|l|}
\hline \multicolumn{1}{|c|}{ Char./ Subchar. } & \multicolumn{1}{|c|}{ Definition } \\
\hline $\begin{array}{l}\text { Supplier } \\
\text { structure }\end{array}$ & $\begin{array}{l}\text { Description of the organizational structure of the } \\
\text { supplier company }\end{array}$ \\
\hline $\begin{array}{l}\text { Positioning and } \\
\text { Strength }\end{array}$ & $\begin{array}{l}\text { Description of the position and orientation of the } \\
\text { supplier company in the market }\end{array}$ \\
\hline Reputation & $\begin{array}{l}\text { Capability of the supplier to perform similar pro- } \\
\text { jects based on past experiences and certifications }\end{array}$ \\
\hline Services Offered & Description of the services offered by the supplier \\
\hline Support & $\begin{array}{l}\text { Description of the support mechanisms offered by } \\
\text { the supplier }\end{array}$ \\
\hline Cost & $\begin{array}{l}\text { Description of the COTS component licensing } \\
\text { options }\end{array}$ \\
\hline Licensing Schema & $\begin{array}{l}\text { Description of the total cost of ownership for the } \\
\text { different licensing options available }\end{array}$ \\
\hline Licensing Costs & $\begin{array}{l}\text { Estimation of the cost for the required production } \\
\text { platform }\end{array}$ \\
\hline Platform Cost & $\begin{array}{l}\text { Estimation of implementation costs based on } \\
\text { similar past experiences }\end{array}$ \\
\hline $\begin{array}{l}\text { Implementation } \\
\text { Cost }\end{array}$ & $\begin{array}{l}\text { Estimation of additional costs for network } \\
\text { operation }\end{array}$ \\
\hline Network Cost & $\begin{array}{l}\text { Detail of the aspects that stand for the out-of-the- } \\
\text { box stability of the product }\end{array}$ \\
\hline Product \\
and customization
\end{tabular}

Table 4. NT-ISO/IEC catalogue.

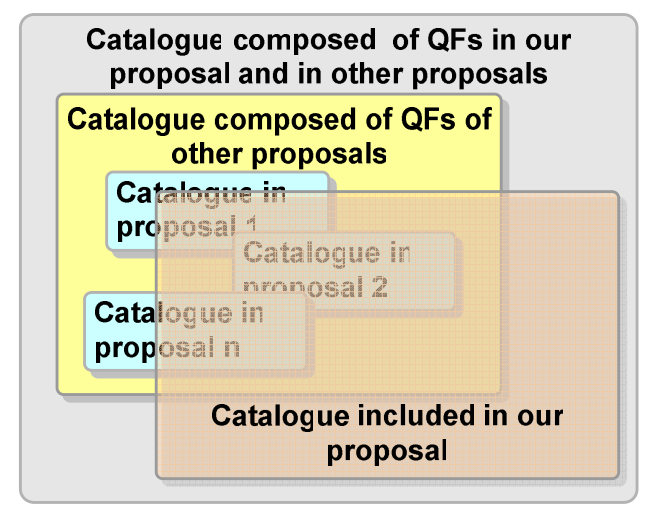

Figure 2: Our catalogue regarding other proposals
Finally it is important to remark that, when the extended NT-ISO/IEC catalogue is used in a particular project more refinement is usually needed for customizing the catalogue for the new environment. However, since the catalogue is very complete, few new quality features will generally be needed. In the next section we present a case study that illustrates this situation.

\section{A Case Study}

ETAPATELECOM is a private but public-founded telecommunications company, based in Cuenca, Ecuador, established in 2002. Currently, ETAPATELECOM provides internet access and data carrying services in several locations of the country. However, the main purpose for its creation is not to focus on these services, but to develop the strategy and perform the deployment of the services included in the objectives of the concession contract (nationwide, public and domiciliary fixed telephone services).

To fulfill its deployment strategy ETAPATELECOM has to face the selection and adoption of several technologies, including several COTS components, required for its operation. A selection process for these COTS components was initiated in 2005 and still ongoing.

\subsection{A COTS-based System Architecture for ETAPATELECOM}

To identify the required COTS components we used the first two activities of the COSTUME (COTS-based Sys Tem qUality Model dEvelopment) method presented in [4]. Using this approach, six COTS components domains were identified to be included in the COTSbased systems architecture projected in ETAPATELCOM (see figure 3): Mediation components (required to interact with telephone switching devices, softswitchs, AAA servers or other telecommunications management equipment); a Telecommunications Billing component; an Enterprise Resource Planning (ERP) component; a Customer Relationships Management (CRM) component; a Balanced Score Card (BSC) component; and a Call Center management component.

Although the original idea was to purchase all of the components, a strategic analysis performed by the senior management resulted in the decision to develop in-house the Billing and CRM components. These components were considered too business-specific, and the ability to fully tailor them to the very dynamic requirements of this kind of organization (commercial plans and offers, new services, combined services packages, etc.), could give a competitive advantage with respect to its competitors. 


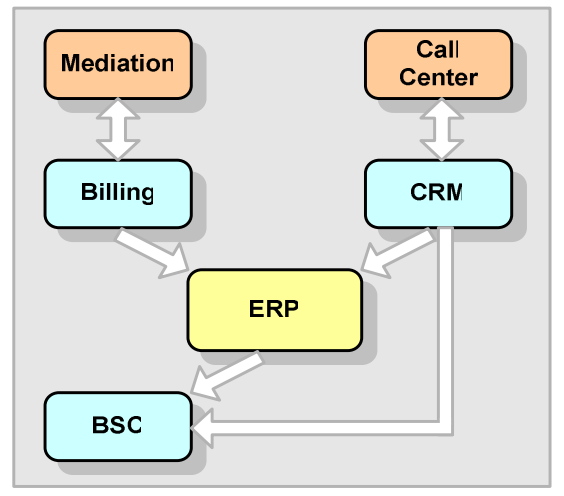

Figure 3: COTS-based system architecture

\subsection{Issuing the Request for Information}

Once the main components of the architecture were identified, the focus of the attention was the project viability. The availability of the required components, the existence of local suppliers with enough experience and capacity to support the required project, the estimated budget and the time schedule, became the major concerns.

We proposed to use the extended NT-ISO/IEC catalogue for generating the information about nontechnical issues. The catalogue was used to create a particular kind of call for tender's document that we call Request For Information forms (RFI). Requirements in a RFI were stated in the form of constraints over the attributes included in the catalogue (technical and nontechnical), using the metrics defined for them. Also suppliers were asked to handle their answers as values resulting from the application of these metrics. In this way, the catalogue became a general framework to state requirements over the required domains, and to describe COTS components capabilities in a uniform way [7] [8]. The resulting descriptions are being currently used to support the negotiation process, making easier the identification of mismatches among components characteristics and the stated requirements (see figure 4).

The use of the extended NT-ISO/IEC catalogue proved to be useful in the practice. When stating requirements the catalogue was easy to handle and requirements were easy to state in relation to the included non-technical attributes. Several situations aroused, most of them in relation to the cases identified in [7], [8]:

- Identification of intrinsic requirements: The existence of the catalogue allowed for the direct statement of requirements over the included attributes. In some way the catalogue acted as a non-technical requirements template, with the advantage that the obtained requirements are parametric (given the metrics values), thus can be reused in several processes (e.g. the National Presence attribute categorised under the Support/Support Channel Location subcharacteristics, can be given the requirement value $\{$ yes, Ecuador , \{yes, USA \} or any other country depending of the required location where the process takes place).

- Elimination of abstract requirements: Because requirements had to be stated in terms of the nontechnical attributes values, there was not room for abstract requirements. For instance let's consider the requirement "Supplier shall be in charge of the implementation", stated prior the use of the catalogue. This requirement was mapped to several non-technical attributes to define the scope of the required service. The metrics of the Organizational Analysis and Alignment, Organizational Change Management and, Parametrization and Adaptation attributes, among others, were set to the YES value in order to constrain the required services.

- Elimination of incorrectly stated requirements: Nontechnical quality features categorized under the extended NT-ISO/IEC catalogue could be used to reformulate incorrectly stated requirements. For instance the cost of a given component was confused with its Total Cost of Ownership (TCO), by people with lack of experience in the adoption of COTS components. A requirement stated as "the cost of the product shall not exceed XXX dollars", was later detailed in terms of the non-technical attributes categorized under the Licensing Costs, Platform Cost, Implementation Cost and Network Cost subcharacteristics. Not only that requirements became more refined, but in this way the doors were open to perform a more complete financial analysis in order to obtain a more approximate TCO.

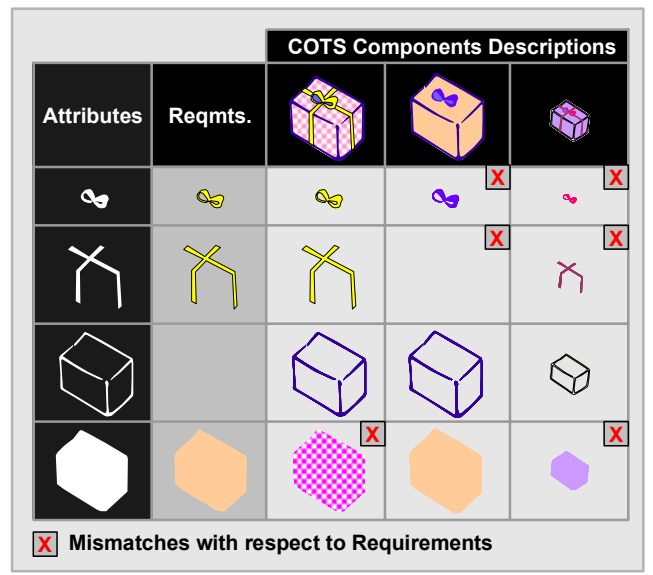

Figure 4: Statement of requirements and RFI answers with respect to an attributes catalogue.

- Implicit extension of requirements: With the use of the catalogue and the stated relationships among quality features, requirements could be implicitly extended. For instance, the Technology Transfer and Training Cost non-technical attribute, categorised under the 
Implementation Cost subcharacteristic, is in relation to the Languages and Compilers non-technical attribute categorised under the Platform Cost/Development Tools. Thus in order to grant technological transfer at least a requirement in relation to the number licences of the languages and compilers required had to be stated.

Finally it is worth to remark that requirements stated in the proposed framework, are measurable, thus more precise and easy to evaluate. The next section analyses the implication of this fact in relation to the answers provided by the suppliers.

\subsection{Obtaining Answers from Suppliers}

Eleven COTS suppliers were invited to present answers to the RFIs in relation to four components; 5 answers were presented in relation to the ERP, 3 in relation to the CRM (although the decision to in-house develop this component was already taken, managers wanted to validate this decision gathering information from available components), and 1 in relation to the BSC and the Call Center Management components. Some of the invited suppliers presented RFIs in relation to more than one component.

Once the answers from the suppliers were available, they were placed in a single matrix, to make easier their management and comparison. The resulting matrix of nontechnical quality features and supplier answers was the basis to support several activities:

- To make easier the identification of mismatches. The answers included in the matrix were described in a uniform way, using the same metrics. This made easy the identification of differences and mismatches among the different proposals and with respect to the stated requirements (e.g. the size of the organization, the vertical market orientation, the provided services, the type of product ownership, etc.). Evaluators focused only in this reduced set of non-technical quality features, instead of the whole set, prioritizing the concepts that could make a difference among the products, their total cost of ownership or the proficiency of their suppliers to successfully complete the implementation process. A subset of 30 non-technical attributes where mismatches existed was used for this analysis.

- To identify potential risks. The answers to some of the non-technical attributes proved to be useful to identify potential risks e.g., suppliers with a reduced consulting team addressing several projects at the time, suppliers excessively relaying in third party support and services, suppliers of two competing products at the time, or the lack of participants providing some required services. More specifically in the case of ETAPATELECOM, one of the participants was ranked with a high level of risk since most of the development effort was to be conducted by third party subcontracted engineers, without providing any means for quality assessment.

- To define a prospective budget. Cost related attributes include not only licensing fees but costs in relation to the platform (hardware and software), consulting services and development tools, as well as recurring fees. These allowed for the definition of a complete budget and the total cost of ownership at the short, medium and long time. In some of the RFIs issued by ETAPATELECOM the cost related attributes were particularly important not only to estimate the budged, but also to identify additional components required. This was the case of the RFI issued for the Call Center component which revealed the need for special hardware components required as part of the operational platform. As consequence the project budged had to be modified and additional requirements had to be issued to support their selection.

- To propose an initial schedule. Part of the nontechnical quality features in the catalogue are in relation to the methodology to be applied, the estimated number of hours to perform each of the required services and the effort required to get the component running, based on past similar experiences. This allowed the definition of an initial schedule including the main activities to be performed, the estimated time for their conclusion and the resources (people and money) required.

- To analyze the viability of the project. There can be several problems hampering the viability of the project: Some of the components may not be available in the market; some of them are due to work only in proprietary platforms; some of them are not designed to interoperate with other components; etc. In addition, the adoption of the components may not align with the organizational goals, schedule or budget, making the project not feasible to be conducted in the practice. Although some of the features to perform this analysis are technical ones, some non- technical attributes are also well suited to support this purpose, not only cost related ones, but also others such as product market orientation, the initial effort required to get the component to work, or even the lack of suppliers providing answers in relation to a particular component.

\section{Conclusions}

In this paper we have presented an approach for dealing with non-technical issues required to support several activities in COTS-based systems lifecycle, with the same layout as proposed in the ISO/IEC 9126-1 standard. We have shown how this catalogue may be effectively used for issuing RFI to help gathering and comparing information about COTS products and suppliers. 
We have proposed a 3-level catalogue of non-technical information. The first level just provides the most abstract non-technical features which remain immutable throughout every single COTS selection process. The second level embraces those features that are considered to appear in most selection processes facilitating identification of applicable features. The third level is devoted to individual selection processes. The catalogue has been validated through several industrial cases and literature survey.

Focusing on the catalogue of non-technical features, the main differences with other approaches are the number on non-technical quality features that we have identified in the extended NT-ISO/IEC catalogue, the way in which they have been organized, and the provision of metrics for evaluating each feature. Our catalogue is much richer than others we know about; it encompasses 180 non-technical quality features (including most of the ones identified in the reviewed approaches) which are arranged in a hierarchical tree-like structure, similar to the one proposed in the well known ISO/IEC 9126-1 software quality standard, outlining a uniform framework well-suited for the evaluation of both technical and non-technical quality features.

As a last distinctive issue, in the introduction we have enumerated a series of applications for which nontechnical attributes are useful during the COTS components selection and implementation lifecycle. Some of these applications have already been validated in industrial cases, whilst others remain under study to asses their practical applicability.

\section{Acknowledgement}

This work has been supported by the research project UPIC, TIN2004-07461-C02-01, MCyT, Spain.

\section{References}

[1] P. Botella, X. Burgués, J.P. Carvallo, X. Franch, G. Grau, J. Marco, C. Quer. "ISO/IEC 9126 in practice: what do we need to know?". Software Measurement European Forum, (SMEF) 2004

[2] M.F. Bertoa, J.M. Troya, A. Vallecillo. "A Survey on the Quality Information Provided by Software Component Vendors". In Proc. of QAOOSE 2003 at $7^{\text {th }}$ ECOOP. 2003.

[3] J.P. Carvallo, X. Franch, "Extending the ISO/IEC 9126-1 Quality Model with Non-Technical Factors for COTS Components Selection". Workshop on Software Quality (WOSQ), 2006.

[4] J.P. Carvallo, X. Franch, G. Grau, C. Quer. "COSTUME: A Method for Building Quality Models for Composite COTSbased Software Systems". International Conference on Quality Software (QSIC), 2004.
[5] http://www.lsi.upc.es/ gessi/QMTool/CQM/Non.htm.

[6] J.P. Carvallo, X. Franch, G. Grau, C. Quer. "Managing NonTechnical Requirements in COTS Components Selection". IEEE Joint Conference on Requirements Engineering (RE), 2006.

[7] X. Franch, J.P. Carvallo, “A Quality-Model-Based Approach for Describing and Evaluating Software Packages". IEEE Joint Conference on Requirements Engineering (RE), 2002.

[8] X. Franch, J.P. Carvallo, "Using quality models in software package selection". IEEE Software, 20(1), 2003.

[9] International Organization for Standarization. ISO Standard 9126: Software Engineering - Product Quality, part 1. International Organization for Standarization, 2001.

[10] International Organization for Standarization. ISO Standard ISO/IEC12119: Information Technology-Software packages-Quality requirements and testing. International Organization for Standarization, 2001.

[11] D. Kunda, L. Brooks. "Identifying and classifying processes (traditional and soft factors) that support COTS component selection: a case study". European Journal of Information Systems, 9(4), 2000.

[12] M. Krystkowiak, V. Bétry, E. Dubois. Efficient COTS Selection with OPAL Tool. International Workshop on Models and Processes for the Evaluation of off-the-shelf Components (MPEC). 2004.

[13] J. Kontio. "A case study in applying a systematic method for COTS selection". International Conference on Software Engineering (ICSE), 1996.

[14] D. Kunda. "STACE: Social Technical Approach to COTS Software Evaluation". Component-Based Software Quality Methods and Techniques. 2003. LNCS 2693, pp. 64-84.

[15] Powell, A., Vickers, A., Lam, W., "Evaluating Tools to support Component Based Software Engineering," International Symposium on Assessment of Software Tools, IEEE Computer Society, Los Alamitos, pp. 80-89, 1997.

[16] B.S.Sahay, A.K.Gupta. "Development of Software Selection Criteria for Supply Chain Solutions". Industrial Management \& Data Management, 103/2, 2003.

[17] M. Torchiano, L. Jaccheri, C.-F. Sørensen and A. I. Wang. "COTS products characterization". International Conference on Software Engineering and Knowledge Engineering (SEKE), 2002

[18] M. Morisio, M. Torchiano. "Definition and classification of COTS: a proposal". 1st ICCBSS, 2002.

[19] B. Wong, D. R. Jeffery. "A Framework for Software Quality Evaluation". Conference on Product Focused Software Process Improvement, PROFES'02. Finland, December 2002. LNCS 2559, pp. 103-118.

[20] P. A. Oberndorf, L. Brownsword, E. Morris, C. Sledge, B. Wong, D. R. Jeffery. "Workshop on COTS-Based Systems". Special report CMU/SEI-97-SR-019, 1997.

[21] J.P. Carvallo, X. Franch, C. Quer. "Un Catálogo de Factores de Calidad para la Definición de Requisitos No Técnicos en la Selección de Componentes COTS". Workshop on Requirements Engineering (WER), 2006. 